THE aim of this study was to examine glycoconjugate secretion in human airways with and without an epithelium. Glycoconjugate release in supernatants derived from human airways in vitro was determ ined using an ELISA assay with an anti-human mucin monoclonal antibody (MAb 3D3). This monoclonal antibody reacted strongly with $L^{b}$ antigen but also recognized in vitro $\mathrm{Le}^{\mathrm{a}}$ and $\mathrm{Le}^{\mathrm{y}}$ determinents. In 11 of the 34 different lung samples $(32 \%)$ studied the glycoconjugate levels were below the threshhold of detection for this assay. The mean basal secretion of glycoconjugates in human airways in vitro was $100 \pm$ $28 \mu \mathrm{g} / \mathrm{g}$ tissue (Period I; $n=23$ different lung samples). The amount of glycoconjugate measured in the medium derived from human isolated bronchial ring preparations did not change under control conditions during the course of the experimental procedure (Period I; $128 \pm 46 \mu \mathrm{g} / \mathrm{g}$ tissue and Period II; 159 $\pm 48 \mu \mathrm{g} / \mathrm{g}$ tissue; $n=13$ paired lung samples). In the supernatants of airway preparations $w$ ith an intact epithelium the amount of glycoconjugates detected was $90 \pm 38 \mu \mathrm{g} / \mathrm{g}$ tissue (Period I; $n=12$ different lung samples) and removal of the epithelium did not alter this basal glycoconjugate release $(94 \pm 60 \mu \mathrm{g} / \mathrm{g}$ tissue: Period I, $n=8$ different lung samples). The absence of the epithelial layer was confirmed by histological evaluation. Me thacholine $(100 \mu \mathrm{M})$ induced a 10 - and four-fold increase in glycoconjugate release from airways with and without an epith elium, respectively. In con trast, in preparations with an epithelium, LTD $_{4}$ $(10 \mu \mathrm{M})$ and anti-IgE (dilution: $1 / 1000)$ did not cause an increase of glycoconjugate release. The methacholine difference between airways with and without an epithelium was not significantly different $(P>0.10)$. However, a treatment with atropine $(100 \mu \mathrm{M})$ prevented the increase of glycoconjugate release in preparations with an epithelium. These data derived from a limited number of experiments suggest that the epithelium may not regulate the basal or stimulated release of glycoconjugates from isolated human airways.

Key words: Human airways, Glycoconjugate, Monoclonal antibody, Epithelium, Le ${ }^{\mathrm{b}}$ antigen, Secretion

\section{Glycoconjugate secretion in human airways in vitro. effects of epithelium removal}

\author{
H. Sossé-Alaoui, ${ }^{2}$ C. Labat, ${ }^{2}$ I. Gorenne, ${ }^{2}$ V. Thomas \\ de Montpreville, ${ }^{1} \mathrm{~J}$ Bara $^{3}$ and C. Brink ${ }^{2, \mathrm{CA}}$
}

${ }^{1}$ Laboratoire d'Anatomopathologie and ${ }^{2}$ CNRS ERS 566, Hôpital Marie-Lannelongue, 133, ave de la Résistance, 92350 Plessis-Robinson, France; ${ }^{3}$ INSERM U-55, Hôpital Saint-Antoine, 184, rue du Faubourg Saint-Antoine, 75012 Paris, France

${ }^{\mathrm{CA}}$ Corresponding Author

Tel: $(+33) 140942800$

Fax: (+33) 146301208

Email: brink@pratique.fr

\section{Introduction}

Early studies ${ }^{1,2}$ showed that the constituents of mucus are derived from goblet cells and the submucosal glands. Coles and coworkers ${ }^{3}$ using ${ }^{14} \mathrm{C}$-glucosamine, measured radiolabelled glycoprotein in the tissue medium from airway preparations and demonstrated that the epithelium did not contribute to the basal secretion in dog respiratory tract. However, removal of the epithelium significantly decreased the secretion of sulphated glycoprotein ${ }^{2}$ suggesting that some secretory constituents may originate from the goblet cells in the epithelial layer. In contrast, Sasaki and coworkers ${ }^{4}$ demon- strated that in cat airways the epithelium modulated the secretory activity of the submucosal glands. Since the epithelium decreased the methacholine induced glandular secretion, these authors suggested the liberation of an epithelium inhibitory factor which modulated the mucin release. In contrast, Sherman and coworkers ${ }^{5}$ using methacholine demonstrated a significant release of mucus glycoproteins in the absence of the epithelium. These latter results would suggest that the epithelium does not contribute significantly to the glycoproteins secreted. While some of these differences may be related to the species in which the experiments were performed, there is little information available 
on the influence of the epithelium in modulating the secretory activity in human airways.

While the principal constituents of mucus are the mucins, a variety of proteins, glycoconjugates (serum type glycoproteins and proteoglycans) and glycolipids are also produced and secreted. ${ }^{6-8}$ In an attempt to characterize those factors which constitute respiratory secretion, Saint George and coworkers ${ }^{9}$ showed that a number of monoclonal antibodies reacted with material in goblet cells and/or submucosal mucus gland cells, data which have been confirmed by other investigators. ${ }^{10}$ Recently, Emery and coworkers ${ }^{11}$ have prepared an anti-human mucin MAb against purified human respiratory mucins. These authors indicated that this anti-human MAb 3D3 was not specific for respiratory mucin but reacted, in fact, strongly with the Lewis b ( $\mathrm{Le}^{\mathrm{b}}$ ) antigen, but also recognized $\mathrm{Le}^{\mathrm{a}}$ and $\mathrm{Le}^{\mathrm{y}}$ determinents using synthetic oligosaccharides. These investigators also demonstrated that in human airways the MAb 3D3 stained goblet cells and mucous cells of the submucosal glands as well as human epithelial cells in culture. ${ }^{12}$ These observations suggested that this monoclonal may be a useful tool to monitor secretory activity in human airways.

The aim of this study was to examine glycoconjugate secretion in human airways in vitro under basal conditions and subsequent to methacholine stimulation. In order to evaluate the role of the epithelium, these experiments were performed in human bronchial ring preparations with an intact epithelium or in bronchial rings in which the epithelium had been removed.

\section{Materials and Methods}

\section{Tissues}

Human lung tissues was obtained from patients $(n=$ 34) who had undergone surgery for lung carcinoma. Subsequent to the resection of lung, the subsegmental bronchi were dissected free from parenchymal tissue and washed with Tyrode's solution. The composition of the Tyrode's solution was (mM): $\mathrm{NaCl} 139.2, \mathrm{KCl} 2.7$, $\mathrm{CaCl}_{2} 1.8, \mathrm{MgCl}_{2}$ 0.49, $\mathrm{NaHCO}_{3} 11.9, \mathrm{NaH}_{2} \mathrm{PO}_{4} 0.4$ and glucose $5.5 \mathrm{pH} 7.4$. Bronchial tissues were cut as rings (4-7 mm, internal diameter and $100-400 \mathrm{mg}$, wet weight). Bronchial preparations with and without epithelium were examined. The epithelium was removed by gently rubbing the luminal surface of the bronchial preparations with a moistened cotton swab.

\section{Histological studies}

Bronchial rings were fixed in formalin for $24 \mathrm{~h}$, dehydrated, emdedded in parafin and sections $(10 \mu \mathrm{m})$ were cut and stained with haematoxylin and eosin $(2.5 \%)$ to evaluate general morphology.
The method for peroxidase staining was performed as previously described, ${ }^{13}$ using Dako Kit LSAB-2. Briefly, tissue sections were deparaffinized with toluene, rehydrated with ethanol and washed with PBS. Endogenous peroxydases were eliminated with $\mathrm{H}_{2} \mathrm{O}_{2}$ ( $3 \%$ for $5 \mathrm{~min}$ ). Tissue sections were treated with blocking serum (casein $0.25 \%$ in PBS; Dako) for inhibition of cross immunological reactions. The tissues were incubated ( $10 \mathrm{~min})$ with anti-mucin $3 \mathrm{D} 3$ antibody and washed with PBS. Thereafter, the sections were incubated $(10 \mathrm{~min})$ with peroxidase coupled to streptavidine and peroxidase activity was developed using diaminobenzidine $/ \mathrm{H}_{2} \mathrm{O}_{2}$. Tissues were counter-stained with Harris haematoxylin.

\section{Functional studies}

The preparations were set up in a microtitre plate (24 wells) containing Tyrode's solution ( $1 \mathrm{ml}$ ) and allowed to equilibrate for $1 \mathrm{~h}$ in a humidified incubator $\left(37^{\circ} \mathrm{C}\right.$, $5 \% \mathrm{CO}_{2} /$ air). At the end of this equilibration period, the medium was exchanged and fresh Tyrode's solution was added. The tissues were then maintained for 1 hour (Period I: basal release). The medium was collected and replaced with Tyrode's solution or Tyrode's solution containing atropine $(100 \mu \mathrm{M})$. After 30 min (treatment), the medium was exchanged with Tyrode's solution or Tyrode's solution containing either atropine $(100 \mu \mathrm{M})$ and/or methacholine $(100 \mu \mathrm{M})$. In some experiments, subsequent to the incubation in Tyrode's solution ( $30 \mathrm{~min}$ ) the bronchial preparations were stimulated with either $\mathrm{LTD}_{4}$ $(10 \mu \mathrm{M})$ or anti-IgE (dilution 1/1000). Following a $1 \mathrm{~h}$ exposure to these agents (Period II: post-treatment), the supernatants were again collected. The supernatants from Period I and Period II were stored at $-20^{\circ} \mathrm{C}$. Prior to determination of glycoconjugates (ELISA), dithiotreitol (DTT) $0.1 \%$ in PBS solution was added to these samples for $15 \mathrm{~min}$ at $37^{\circ} \mathrm{C}^{14}$ to permit solubilization of mucus particulates present in the supernatants.

\section{Glycoconjugate determination}

The antigen and MAb 3D3 were a gift from Bayer plc (UK) and details concerning purification and preparation have recently been published. ${ }^{11}$

The glycoproteins secreted in supernatants of human bronchial rings were detected by ELISA using the MAb 3D3. Microplates (Nunc-Immunoplate Maxisorp) were coated with a solution of MAb (dilution: $1 / 5000$ in PBS) and incubated overnight at $4^{\circ} \mathrm{C}$. The plates were washed twice with $200 \mu$ of PBS-Tween 20 (dilution: 1/1000) employing a microplate washer, unbound sites were blocked with $(30 \mathrm{mg} / \mathrm{ml})$ BSA diluted in PBS for $1 \mathrm{~h}$ at $37^{\circ} \mathrm{C}$. The plates were washed with a dilution of purified human 3D3 antigen standard in PBS-Tween-20 $(1-500 \mathrm{ng} / 50 \mu \mathrm{l})$ and the 
supernatants of the bronchial ring preparations were distributed in the wells and incubated for $1 \mathrm{~h}$ at $37^{\circ} \mathrm{C}$. Following, three washes with Tris-Tween-20, the MAb 3D3 mixed with normal mouse serum and antimouse immunoglobulin IgG conjugated with alkaline phosphatase (1/500 in Tris-polyethylenglycol (PEG at $4 \%$ ) was added to wells and incubated for $1 \mathrm{~h}$ at $37^{\circ} \mathrm{C}$. The plates were washed twice with TrisTween-20 and developed using a solution of p-nitrophenylphosphate (pNpp) diluted in $0.2 \mathrm{MTris}$ buffer $\mathrm{pH}>8$ to give a final concentration $(1 \mathrm{mg} / \mathrm{ml})$ substrate. The reaction was terminated $(15-20 \mathrm{~min})$ when the optical densities (OD) correspond to maximal concentration from 3D3 antigen standard attained 0.8 OD units. Optical densities were measured with a Titertek-Multiskan (Labsystems) microplate reader using a wavelength of $405 \mathrm{~nm}$. The amount of glycoconjugate released was interpolated from the 3D3 antigen standard curve. A standard curve with dithiotreitol was carried with different amount of 3D3 antigen $(1-250 \mathrm{ng} / 50 \mu \mathrm{l})$, the dithiotreitol $(0.1 \%)$ was added to the maximal concentration of antigen and serial dilutions were subsequently performed. Since the monoclonal antibody 3D3 is directed specifically against the $\mathrm{Le}^{\mathrm{b}}$ antigen only the supernatants of $\mathrm{Le}^{\mathrm{b}}$ individuals in which measurable levels of glycoconjugate were observed, are presented in the results section. In lung samples from 11 of the 34 different patients examined (approximately $30 \%$, the $\mathrm{Le}^{\mathrm{b}}$ antigen was not detected. The percentage of different lung samples in which the $\mathrm{Le}^{\mathrm{b}}$ antigen was detected was similar to the population estimate for $\mathrm{Le}^{\mathrm{b}}$ antigen carrying subjects.

\section{Source of products}

Plates (maxi-sorp Nunc), Tris (Prolabo), polyethylene glycol 6000 (Merck), Kit LSAB-2 for immunolabelling containing diaminobenzidine (Dako Laboratories). All the remaining products; methacholine, atropine, mouse serum, anti-mouse immunoglobulin coupled with alkaline phosphatase, bovine serum albumin, dithiotreitol (DTT), Tween-20, $p$-nitrophenylphosphate (pNpp) were from Sigma Chemical Co., USA. The $\mathrm{LTD}_{4}$ was a gift from Dr P. J. Gardiner (Bayer plc). The sheep antiserum to human $\operatorname{IgE}$ (anti-IgE) was obtained from Nordic Immunological Laboratories, Tilberg, the Netherlands.

\section{Calculation}

The data are represented as $(\mu \mathrm{g} / \mathrm{g}$ tissue) or (\% of basal level, that is, Period II/Period I $\times 100)$. All results are means \pm SEM and $n$ indicates the number of lung samples. Statistical analysis was performed using Student's $t$-test or Mann-Whitney rank sum test. A value $(P<0.05)$ was taken as an indication of significance.
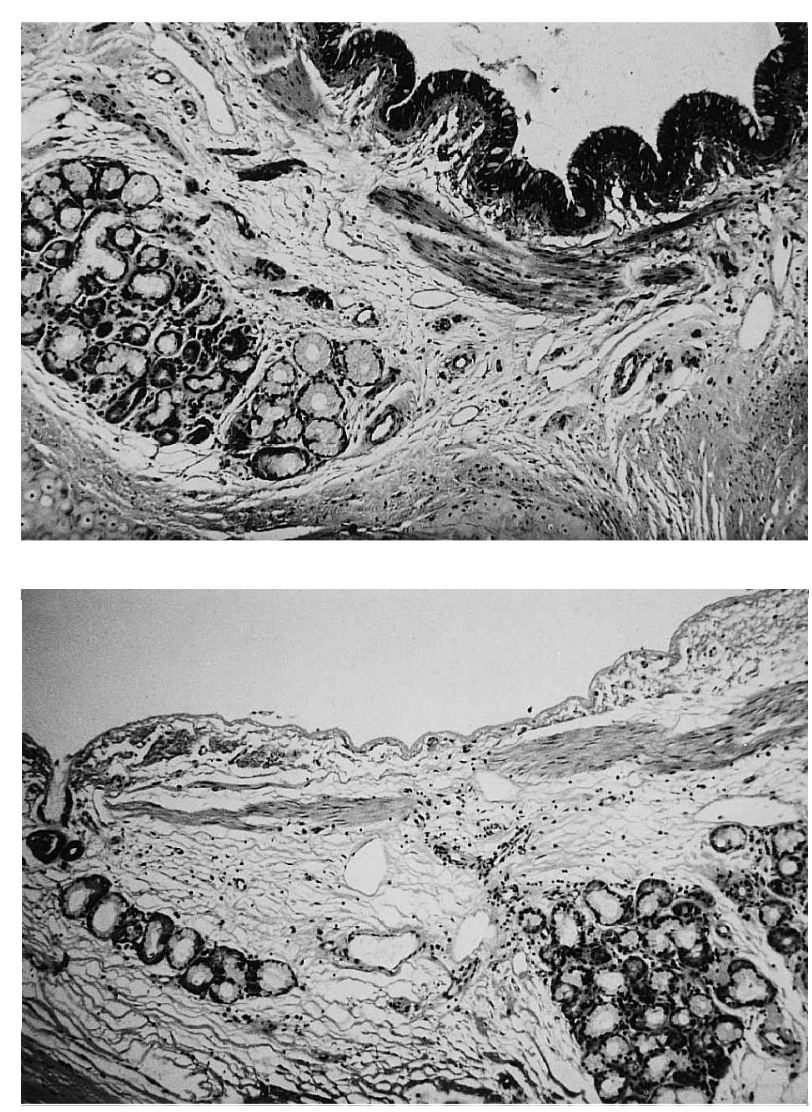

FIG. 1. Top: Morphological aspects of human bronchial preparation with an intact epithelium. The presence of a pseudostratified epithelium with goblet cells and ciliated cells was observed (magnification $\times 100$ ). Bottom: Human bronchial preparations without epithelium. Tissues were stained with haematoxylin and eosin (magnification $\times 50$ ).

\section{Results}

\section{Histological data}

Mechanical removal of the epithelium by rubbing the luminal surface of human isolated bronchial ring preparations led to the complete obliteration of the epithelium while the basement membrane was left intact (Fig. 1). In human bronchial ring preparations after treatment with MAb 3D3, staining showed that this MAb 3D3 antibody was associated with two specific tissue regions, namely, the epithelial layer and submucosal glands (Fig. 2).

\section{Functional data}

The DTT did not alter the 3D3 antigen standard curve (Fig. 3.). In 11 of the 34 different lung samples studied in this assay (32\%), the glycoconjugate levels were below the threshhold level of detection. The mean basal secretion of glycoconjugates in human airways in vitro was $100 \pm 28 \mu \mathrm{g} / \mathrm{g}$ tissue (Period I; $n=23$ different lung samples). The amount of glycoconjugate measured in the medium, derived from human isolated bronchial ring prepara- 


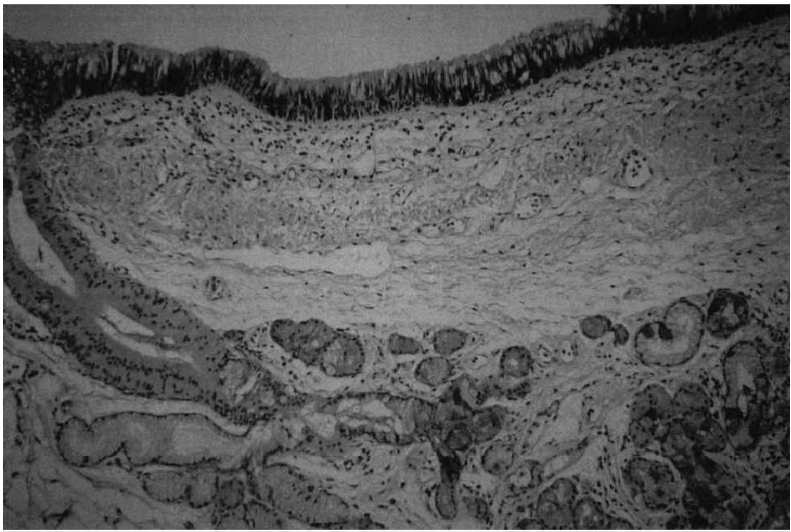

FIG. 2. Immunohistochemical labelling of human bronchus with MAb 3D3. The MAb 3D3 labelled both the epithelium including mucus goblet cells and mucus cells of the submucosal glands (magnification $\times 40$ ) .

tions, did not change under control conditions during the course of the experimental procedure (Period I; $128 \pm 46 \mu \mathrm{g} / \mathrm{g}$ tissue and Period II; $159 \pm$ $48 \mu \mathrm{g} / \mathrm{g}$ tissue; $n=13$ paired lung samples). In the supernatants of airway preparations with an intact epithelium the amount of glycoconjugates detected was $90 \pm 38 \mu \mathrm{g} / \mathrm{g}$ tissue (Period I; $n=12$ different lung samples) and removal of the epithelium did not alter this basal glycoconjugate release $(94 \pm 60 \mu \mathrm{g} / \mathrm{g}$ tissue: Period I, $n=8$ different lung samples). The absence of the epithelial layer was confirmed by histological evaluation.

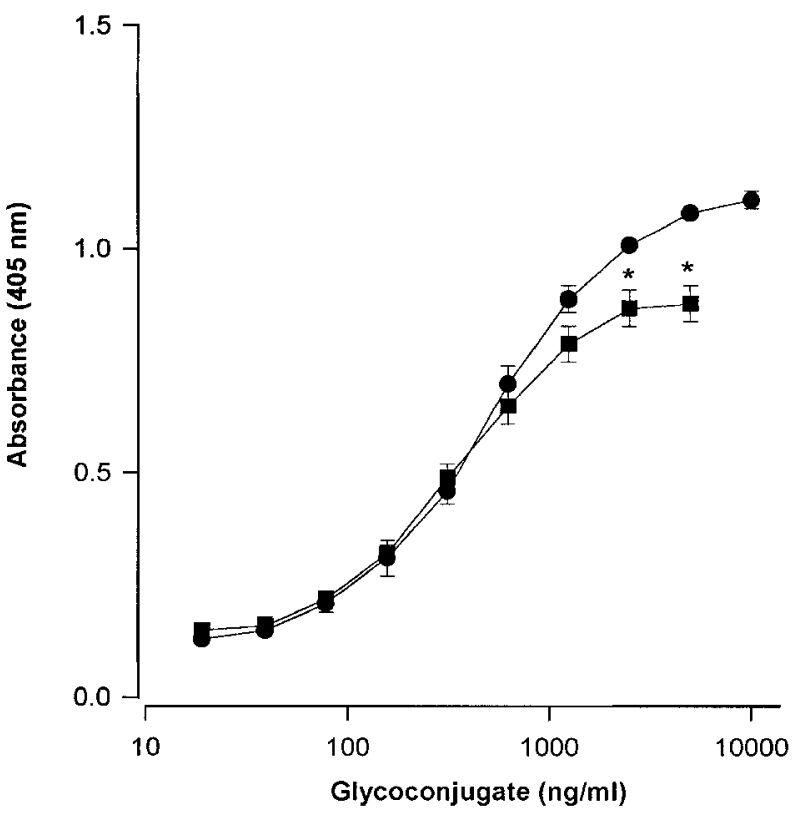

FIG. 3. Effects of DTT on 3D3 antigen standard curve (ELISA). Standard curve with $(\boldsymbol{\square} ; n=6)$ or without $(\boldsymbol{\bullet} ; n=3)$ DTT. The DTT $(0.1 \%)$ was added to the standard maximal concentration of 3D3 antigen and serial dilutions were performed. Results are presented as glycoconjugate $(\mathrm{ng} / \mathrm{ml})$. Values are means \pm SEM and $*$ indicates $P<0.05$ (Student's $t$ test).

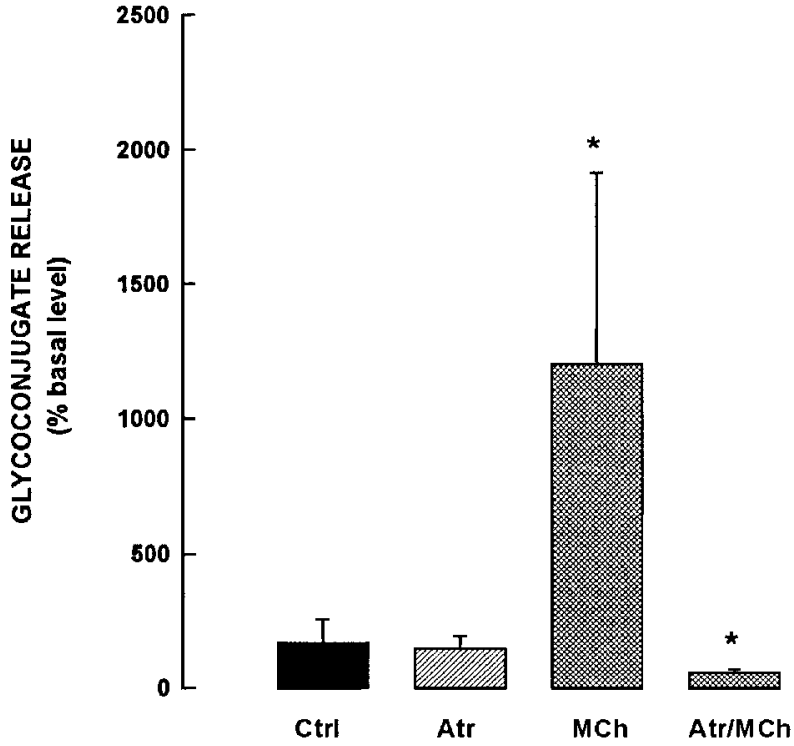

FIG. 4. The effects of muscarinic agents on glycoconjugate release from human bronchial preparations with intact epithelium. Unstimulated tissues (Ctrl; $\boldsymbol{n}=7$ ) and preparations treated with either atropine (Atr, $100 \mu \mathrm{M} ; n=4)$, methacholine (MCh, $100 \mu \mathrm{M} ; n=7$ ) or atropine and methacholine (Atr/MCh, $100 \mu \mathrm{M} ; \boldsymbol{n}=4)$. Results are represented as $\%$ basal release. Values are means \pm SEM and $(n)$ indicates number of different lung samples. (*) indicates $P<0.05$ (Mann-Whitney rank sum test).

In human isolated bronchial ring preparations with an intact epithelium methacholine $(100 \mu \mathrm{M})$ produced a significant increase in the amount of glycoconjugate detected in the medium (Fig. 4). In contrast, no significant change was observed in human bronchial preparations stimulated with either $\mathrm{LTD}_{4}(10 \mu \mathrm{M} ; n=3,48 \pm 24 \%)$ or anti-IgE (dilution $1 / 1000 ; n=5,76 \pm 17 \%$ ). The 10 -fold increase in glycoconjugate release induced by methacholine was attenuated by atropine $(100 \mu \mathrm{M})$. Results derived from similar experiments performed in bronchial rings where the epithelium had been removed are presented in Fig. 5. These data demonstrate that removal of the epithelium did not significantly alter either the basal or stimulated levels of glycoconjugate in the tissue medium.

\section{Discussion}

MAb 3D3, a marker of secretory glycoconjugates ${ }^{11,12}$ was used to determine glycoconjugate release in human airways in vitro. Histochemical analysis revealed that the glycoconjugates which reacted with MAb 3D3 were associated with both the epithelium and the glandular mucus cells of the human bronchus. Methacholine appeared to be the most effective agent to stimulate glycoconjugate release in this model. In addition, the amounts of glycoconjugates detected (basal and stimulated levels) as measured with the MAb 3D3 were not dependent on the presence of the 


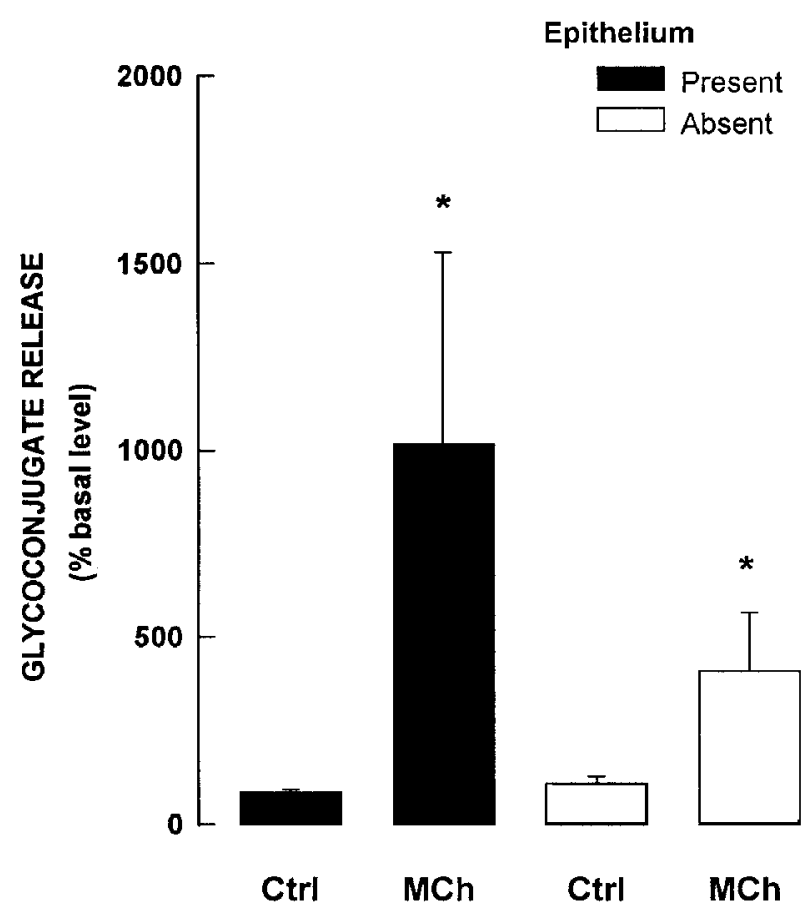

FIG. 5. Glycoconjugate release from human bronchial preparations either with $(\square)$ or without $(\square)$ epithelium. The preparations were unstimulated (Ctrl) or stimulated (MCh, $100 \mu \mathrm{M})$. Values are means \pm SEM from 5-12 lung samples. (*) indicates $P<0.05$ (Mann-Whitney rank sum test).

epithelium since removal of this layer did not significantly alter either the basal or methacholine induced release.

Stahl and Ellis ${ }^{2}$ published a biochemical study showing that removal of the epithelium in $\mathrm{dog}$ airways permitted the detection of several glycoproteins thereby assigning the release of different substances to the epithelium or the mucosal glands of the respiratory tract of this species. Removal of the epithelium produced a significant decrease in the secretion of sulphated glycoproteins suggesting that goblet cells in the epithelium were responsible for these constituents. In addition, these authors also showed that while the epithelial layer and the mucosal glands secrete different macromolecules, they also interacted in the formation of the larger glycoconjugates which are released into the airway lumen.

Previous reports in human airway tissues ${ }^{6,10,14}$ have demonstrated that there was little or no change in basal secretion under control conditions, however, methacholine induced significant increases in secretory activity. The results (present report) confirm these initial observations and are in agreement with data derived from other species, such as the cat. In contrast, in this model (present report) $\mathrm{LTD}_{4}$ and anti$\mathrm{IgE}$ did not induce glycoconjugate release. These results are different from previous reports where secretory activity was assessed using radioactive markers. Marom and coworkers ${ }^{15}$ showed a small increase in release from human airways in vitro $(40 \%$ above control levels) using either $\mathrm{LTC}_{4}$ or $\mathrm{LTD}_{4}$. These data were also supported by the investigation of Coles and coworkers ${ }^{16}$ who demonstrated a similar leukotriene-induced secretory release from human airways. However, radioactive elements may be incorporated into several cells and mark a variety of molecules, ${ }^{17}$ these differences in results may be explained in part by the specificity of the markers employed to determine secretory activity.

However, removal of the epithelium did not significantly modify either the basal secretion or that induced by methacholine stimulation (present report) when the MAb 3D3 was used to evaluate glycoconjugate release from human airways. Therefore species differences may also exist since Sasaki and coworkers ${ }^{4}$ showed that in the respiratory tract of the cat the epithelium modified the secretory activity of the submucosal glands. The data from human airways (present report) would also suggest that the methacholine is acting principally at the glandular level. The lack of cholinergic response at the goblet cell level may be due to the absence of neuronal inputs ${ }^{18}$ at the surface epithelium. In addition, Mak and Barnes ${ }^{19}$ using an autoradiographic technique in human airways demonstrated that muscarinic receptors were not detected in the epithelial layer, since no radiolabel was observed, although label was detected in the region of the glands. Such results would suggest that muscarinic receptors may not be present in the epithelium in human airways. However, a recent publication has demonstrated that muscarinic receptor mRNA is detected in the human respiratory epithelium. ${ }^{20}$ While the autoradiographic technique may not provide adequate sensitivity to detect muscarinic receptors, their location and function in the epithelium has not been adequately evaluated.

While initial reports showed that epithelial cells in culture fail to secrete mucin and/or mucin-like glycoproteins, ${ }^{2}$ recent studies using human epithelial cells in culture have demonstrated that a number of substances including mucins could be detected after several weeks in culture. ${ }^{12}$ While these investigators demonstrated that epithelial cells in culture were stained with the MAb 3D3, no indication as to the function of these epithelial cells was examined. The data from intact human airways in vitro (present report) extend the work of Emery and coworkers ${ }^{11}$ and demonstrate that the MAb 3D3 may also be used to detect basal and methacholine induced secretory activity. However, the functional studies (present report) suggest that while the epithelial layer may fix the MAb 3D3, there was little or no secretory activity detected by MAb 3D3 from this layer. In addition, removal of the epithelium did not modulate either the basal or stimulated release of glycoconjugates in human airway preparations. 
In human airways, the MAb 3D3 may be used as a marker of glycoconjugate release and this secretory activity is principally associated with the submucosal glandular level.

\section{References}

1. Bucher U, Reid L. Development of the mucus-secreting elements in human lung. Thorax 1961; 16: 219-225.

2. Stahl GH, Ellis DB. Biosynthesis of respiratory-tract mucins. A comparaison of canine epithelial goblet-cell and submucosal-glands secretions. $J$ Biochem 1973; 136: 845-850.

3. Coles SJ, Neill KH, Reid LM. Potent stimulation of glycoprotein secretion in canine trachea by substance P. J Appl Physiol Respir Environ Exercise Physiol 1984; 57: 1323-1327.

4. Sasaki T, Shimura S, Sasaki H, Takishima T. Effect of epithelium on mucus secretion from feline tracheal submucosal glands. J Appl Physiol 1989; 66: $764-770$

5. Sherman JM, Cheng PW, Tandler B, Boat TF. Mucous glycoproteins from cat tracheal goblet cells and mucous glands separated with EDTA. Am Rev Respir Dis 1981; 124: 476-479.

6. Boat TF, Kleinerman JI. Human respiratory tract secretions. Effect of cholinergic and adrenergic agents on in vitro release of protein and mucous glycoprotein. Chest 1975; 67: S32-S35.

7. Matthews LW, Spector S, Lemm J, Potter JL Studies on pulmonary secretions. The over-all chemical composition of pulmonary secretions from patients with cystic fibrosis, bronchiectasis and laryngectomy. $\mathrm{Am}$ Rev Respir Dis 1963; 88: 199-204.

8. Roussel P, Degand P, Lamblin G, Laine A, Lafitte JJ. Biochemical definition of human tracheobronchial mucus. Lung 1978; 154: 241-260.

9. Saint George JA, Cranz DL, Zicker SC, Etchison JR, Dungworth DL, Plopper CG. An immunohistochemical characterization of rhesus monkey respiratory secretions using monoclonal antibodies. Am Rev Respir Dis 1985; 132: 556-563.

10. Logun C, Mullol J, Rieves D, Hoffman A, Johnson C, Miller R, Goff J, Kaliner M, Shelhamer J. Use of a monoclonal antibody enzymetinked immunosorbent assay to measure human respitratory glycoprotein production in vitro. Am J Respir Cell Mol Biol 1991; 5: 71-79.
11. Emery N, PalfäóSB, Place G, Oriol R, Hall RL, Roussel P, Lhermitte M A new monoclonal antibody (3D3) generated with human respiratory mucins and directed against Lew is determinants. Glycobiology 1995; 5: 563-570.

12. Emery N, Place GA, Dodd S, Lhermitte M, David G, Lamblin G, Perini JM, Page AM, Hall RL, Roussel P. Mucous and serous secretions of human bronchial epithelial cells in secondary culture. Am J Respir Cell Mol Biol 1995; 12: 130-141.

13. Hsu SM, Raine L, Fanger H. Use of avidin-Biotin-Peroxidase complex $(\mathrm{ABC})$ in immunoperoxidase techniques. J Histochem Cytochem 1981; 29: $577-580$.

14. Shelhamer JH, Marom Z, Kaliner M. Immunologic and neuropharmacologic stimulation of mucous glycoprotein release from human airways in vitro. J Clin Invest 1980; 66: 1400-1408.

15. Marom Z, Shelhamer JH, Bach MK, Morton DR, Kaliner M. Slow reacting substances, leukotrienes C4 and D4, increase the release of mucus from human airways in vitro. Am Rev Respir Dis 1982; 126: 449-451.

16. Coles SJ, Neill KH, Reid LM, Austen KF, Nii Y, Corey EJ, Lew is RA. Effects of leukotrienes C4 and D4 on glycoprotein and lysozyme secretion by human bronchial mucosa. Prostaglandins 1983; 25: 155-170.

17. Rose MC. Mucins: structure, function, and role in pulmonary diseases. Am. J. Physiol, 1992; L413-L429.

18. Partanen MA, Laitinen A, Hernoven A, Toivanen M, Laitinen LA Catecholamine and acetylcholinesterase-containing nerves in human lower respiratory tract. Histochem 1982; 76: 175-188.

19. Mak JCW, Barnes PJ. Autoradiographic visualization of muscarinic receptors subtypes in human and guinea pig lung. Am Rev Respir Dis 1990; 141 : 1559-1568.

20. Mak JCW, Baraniuk JN, Barnes PJ. Localization of muscarinic receptor subtype mRNAs in human lung. Am J Respir Cell Mol Biol 1992; 7: $344-348$.

ACKNOWLEDGEMENT. The authors would like to thank Sylvie Plante for excellent technical assistance.

\section{Received 3 September 1997;} accepted in revised form 31 October 1997 


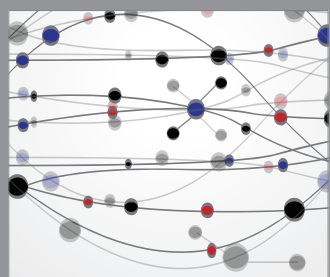

The Scientific World Journal
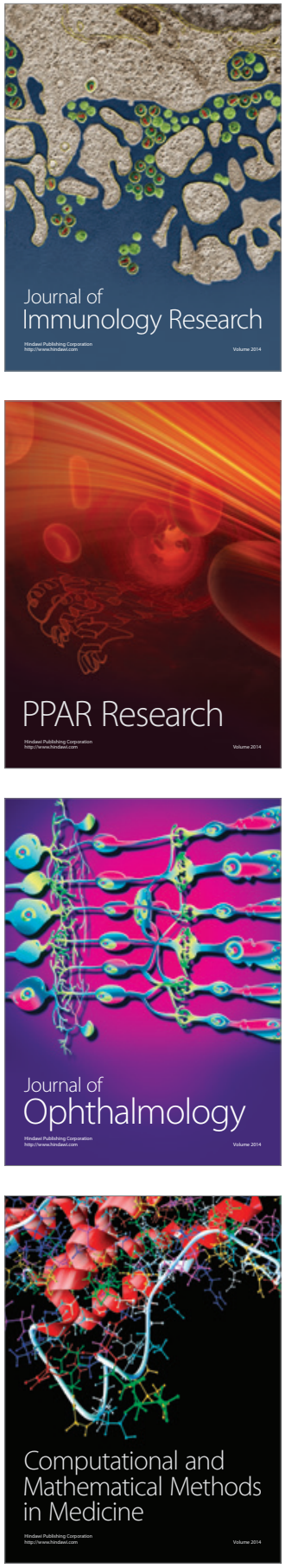

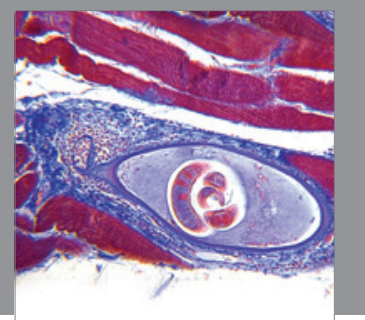

Gastroenterology

Research and Practice
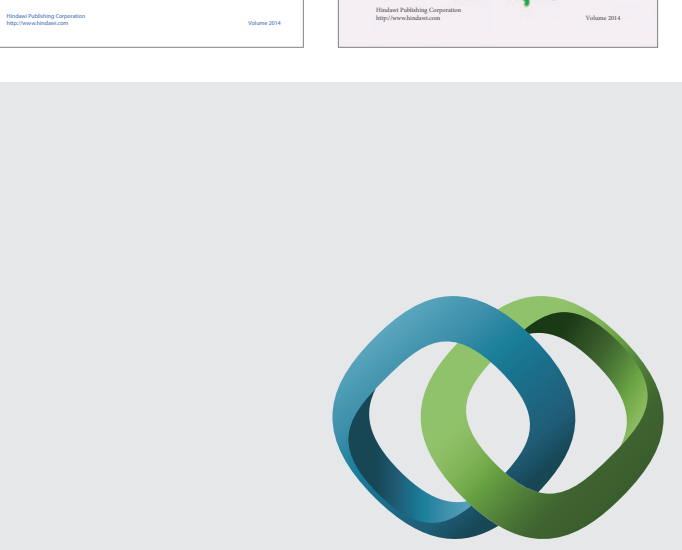

\section{Hindawi}

Submit your manuscripts at

http://www.hindawi.com
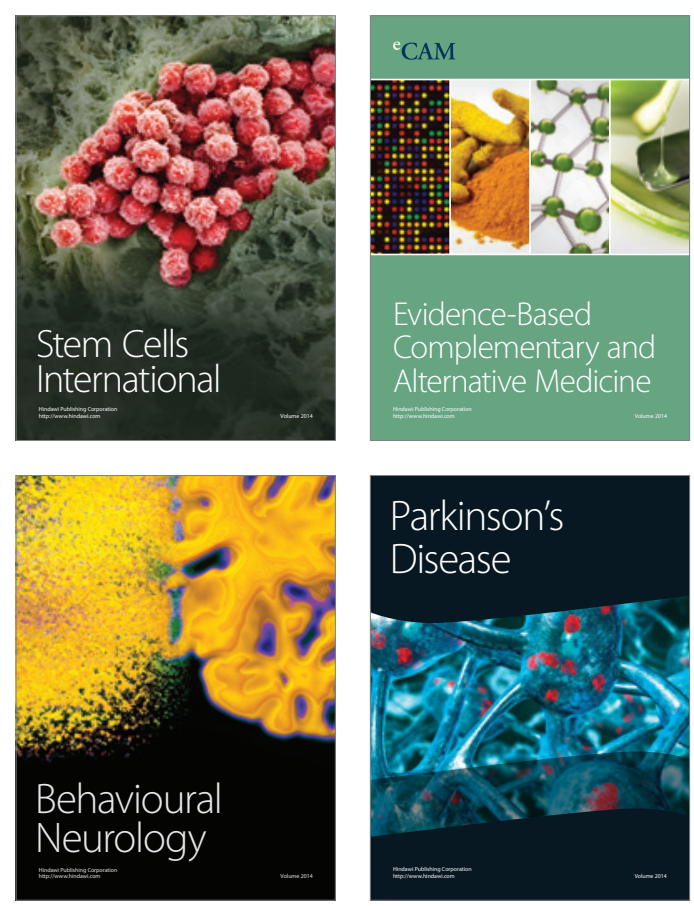

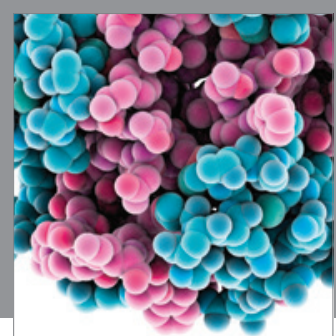

Journal of
Diabetes Research

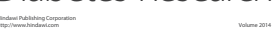

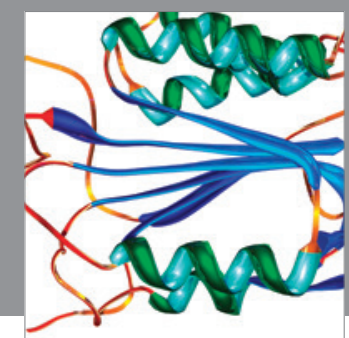

Disease Markers
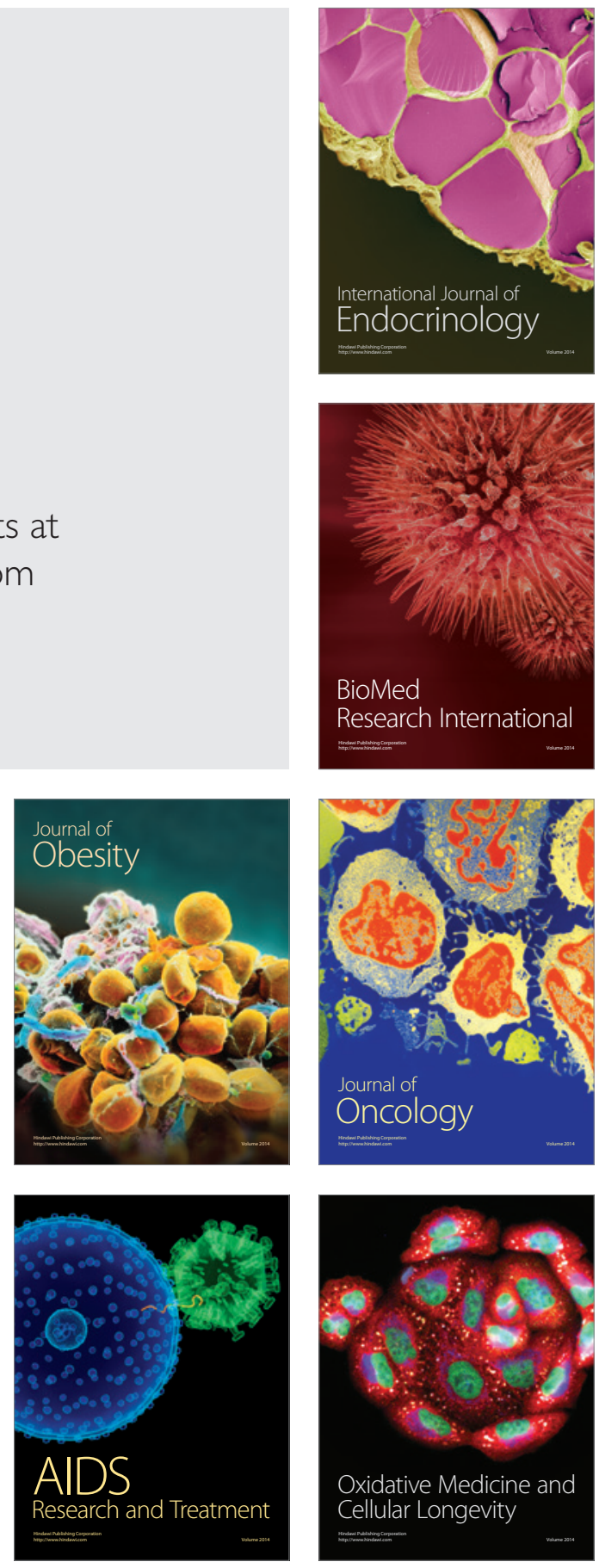